\title{
SUCCESS EVALUATION MODEL FOR PROJECT MANAGEMENT
}

\author{
Radek Doskočil, Stanislav Škapa, Petra Olšová
}

\section{Introduction}

The need for effective planning and management is on the increase along with the increasing complexity and laboriousness of making changes or creating new value. Project management is an ideal tool in this respect (Schwable, 2011; Bočková et al., 2005). The risks associated with deadlines or budgets are extremely serious. Problems of project modelling and simulation are highly topical at the present time, because the application of project management principles is expanding into further areas - change management (Cummings et al., 2016; Yin-xiang, 2013), crisis management (Wimelius \& Engberg, 2015), innovation management (Balkienè, 2013; Dudzevičiūtè \& Tvaronavičienè, 2011; Grossmann, 2009), etc. - which have only very basic features of projects. A number of problems related to change or innovation are now solved using various methods, techniques and tools of project management. The project team often finds itself in a situation in which it must make various project-related decisions. In many cases, such decisions may be classified as serious, as the consequences of the wrong decision may be catastrophic for the project. This is why project teams try to minimise the consequences of wrong decisions. Due to the turbulent and inter-cultural environment of contemporary, often highly complex, projects, these efforts are extremely complicated. Modelling enables the project team to obtain valuable information for future decisionmaking (Colin \& Vanhoucke, 2016; Wauters \& Vanhoucke, 2016). For example, modelling enhances knowledge of the functioning of the system for projects that are still in the proposal phase (model - original). The possibility of experimentation and simulations with the model under changing conditions is a considerable benefit.
Project management employs a number of methods, techniques and tools for project planning and management. Projects must be implemented within planned deadlines with planned resources and costs in order that defined goals are met. This endeavour is the principal goal of project management, whose outcome should be a successfully planned, managed and implemented project. The modelling technique has proved over the long term to be an effective tool used to support decision-making. Decision-making problems are resolved by project teams comprised of experts from various areas and countries in everyday practice for the duration of the project life cycle. A number of decision-making problems are generally resolved in conditions of uncertainty. The risk arising from incorrect decisions represents a considerable threat to the given project or portfolio of projects. There is a natural tendency to try to minimise this risk. Modelling allows project teams to provide valuable information to support future decisionmaking, provides greater knowledge of the functioning of the modelled system, and makes it possible to experiment with the model, in the form of simulation for example, during which the experimental conditions are changed and any change to the behaviour of the model is studied. Methods of network analysis for the production of time, resource and cost analysis of the project are now a traditional way of using the technique of modelling in project management.

The goal of this paper is to present a new expert decision-making fuzzy model for the evaluation of project success. The research in the field of evaluation of project success is based on empirical research. Secondary analysis was used to obtain and process relevant secondary data. General theoretical methods, based on principles of logic and logical thinking (analysis 
- synthesis, induction - deduction, abstraction - concretisation) were used for processing, and in particular for the formulation of conclusions. Fuzzy modelling (fuzzy set theory and fuzzy logic) was used to create the decision-making fuzzy model, see below. The method of guided interviews with experts in project management was used for identification of the rules of the fuzzy model.

\section{Literature Review \\ 1.1 Use of Fuzzy Modelling in Project Management}

Many authors have focused on the theory of fuzzy sets and applications of fuzzy logic in project management. The research by the authors Rodriguez et al. presents a method for the evaluation of risk in IT projects. The method is based in a combination of fuzzy analytic hierarchy process (FAHP) and fuzzy inference system (FIS). FIS is used for the integration of the groups of risk factors. These risk factors are the evaluation criteria of a modified FAHP which minimizes the disadvantages of the classic implementation of FAHP in order to obtain a more intuitive and easily adjustable model for multicriteria decision analysis with a lower computational need. The proposed model takes into consideration the different levels of uncertainty, the interrelationship among groups of risk factors, and the possibility of adding or suppressing options without losing the consistency with previous evaluations (Rodriguez et al., 2016). The research by the authors Rudnik and Deptula (2015) presents the properties, identification issues and utilisation of a new concept of probabilistic fuzzy system for the innovative project risk assessment. For this purpose, a group of risk factors, which influence risk variables, has been chosen. Linguistic risk variables are inputs to the innovation risk assessment system. The structure of fuzzy sets for linguistic values takes into account knowledge of a number of experts. Knowledge is presented as fuzzy rules (IF-THEN) together with probability measures of fuzzy events occurrence in the antecedent and conclusion of rules. The method uses parametric family of triangular t-norms, which facilitates inference parameters optimisation, enables flexible adjustment of a system to empirical data and makes the system more precise (Rudnik \& Deptula, 2015). The research by the authors Liu and Ye presented models for comprehensive evaluating modelling of investment project risk with trapezoid fuzzy linguistic information. A practical example for evaluating the investment project risk is used to verify the developed approach (Liu \& Ye, 2015). The authors Nasirzadeh et al. (2014) present an integrated fuzzy system dynamic modelling for quantitative risk assessment. The values of the various factors, which are characterized by the nature of uncertainty, are defined by fuzzy numbers. The proposed model was simulated at different levels of risk; the optimum level of risk is determined by the point at which the minimum cost of the project (Nasirzadeh et al., 2014). The study of authors Yao-Chen Kuo and Shih-Lu Tong deals with a fuzzy multiple criteria decision-making (FMCDM) approach to systematically assess risk for a metropolitan construction project where twenty risk factors were identified. Triangular fuzzy sets are used for describing of identified factors. The overall risk level of the project depends on the individual impact of individual risk factors; the scheme was evaluated based on the relative impact and likelihood. They note that the suggested model for risk assessment is more reliable, more convenient than traditional statistical methods, and that this model can be used to efficiently identify risks metropolitan construction projects (Kuo \& Lu, 2013). The article "Construction Project Risk Assessment Model" of the authors Zhang and $\mathrm{Li}$ (2011) presents the use of fuzzy mathematical theory and gray relational analysis method in the risk evaluation of construction project. The article by Nieto Morote and-Ruz-Vila (2011) is a methodology for risk assessment based on fuzzy set theory, which is an effective tool for dealing with subjective assessments. The proposed methodology is based on the knowledge and experience gained from many experts. Risk factors are evaluated by qualitative criteria in the form of trapezoidal fuzzy numbers. Fuzzy numbers describe the uncertainty variables at the language level (Nieto-Morote \& RuzVila, 2011). The authors Chanas and Zielinski (2001), Oliveros and Fayek (2005), Bushan and Ravi (2012), Kuchta (2001), Doskočil and Doubravský (2013) have presented fuzzy sets using fuzzy numbers to obtain critical paths of projects. The research by the authors Naeni, Shadrokh and Salehipour (2011) presents a fuzzy-based earned value model with the 
advantage of developing and analyzing the earned value indices, and the time and the cost estimates at completion under uncertainty. An example illustrates how the fuzzy model can be implemented in reality. The same issues by the authors Naeni and Salehipour (2011) present an approach for dealing with fuzzy earned value indices including developing new indices under fuzzy circumstances and evaluating them using the alpha cut method. The proposed model (illustrated in the case study) improves the applicability of the earned value techniques under real-life and uncertain conditions.

\subsection{Project Success}

The issue of project success is also a scientific goal for some authors (Khan \& Rasheed, 2015; Kemmeter, 2014; Schibi, 2013; etc.). The issue of project success is the subject of discussion among a number of experts both in project management and other areas (Joslin \& Muller, 2015; 2013; Todorovic et al., 2015). There are a large number of metrics for the measurement of project success. A number of authors agree on some of these, while others are appearing as new. The studies by authors such as (Yang et al., 2011; Zwikael et al., 2014) consider research into new dimensions of project success. In the study „The Moderating effect of risk on the Relationship between planning and success" the authors deal with examination the relationship between the project planning process and its success. They show the level of success (measured in the form of risk) associated with the project plan. They conclude the high risk projects must be carefully planned. See e.g. (Zwikael et al., 2014). In the opinion of the authors, the metrics differ according to the type of project, the phase in which the project is found, the method of expression: absolute or relative (Samset, 1998), and individual interest groups which often have their own way of perceiving project success (Davis, 2014). The traditional measure of project success is based on what is known as the triple imperative of a project and is associated with the fulfilment of the time period, costs and goals of the project (de Carvalho et al., 2015)cost, and margins. We adopt a contingency approach that evaluates the complexity of the project, according to 4 categories, the effect of industry sector and countries. The methodological approach involved a longitudinal field survey in 3 countries (Argentina, Brazil, and Chile.
In terms of the financial criteria applied, this generally involves the use of the indicators ROI - Return on Investment, NPV - Net Present Value, IRR - Internal Rate of Return (Yinxiang, 2013) and perhaps CBA - Cost-Benefit Analysis (Jaradat et al., 2010). The research by the author Relich presented a computational intelligence approach to predicting the success of new product development projects (Relich, 2015). Data mining techniques, artificial neural networks and the fuzzy neural system are used to identify relationships between the duration of a project phase and other data stored in the information system of an enterprise (Relich \& Muszyński, 2014). The article by McKay and Ellis presented a study which examined the relationship between knowledge sharing processes at the organisational level (organisational learning factors, the unit level, project learning practices) and the success of an IT project (McKay \& Ellis, 2014). The research by the authors Chipulu et al. (2014) presented the impact of cultural values on the importance individuals assign to project success/failure factors. The research by the authors Kloppenborg et al. (2014) presented the role of the executive sponsor in achieving project success. The results provide knowledge that will help executive sponsors decide how to invest their limited time and resources. The authors Mazur et al. (2014) present a model of the associations between the major project managers' personal attributes and project success in the context of the Australian defence industry. In their model, emotional intelligence, cognitive flexibility and systemic thinking were hypothesised to relate to project success, mediated by internal and external stakeholder relationships. This model was tested in an online survey with 373 major project managers. Emotional intelligence and cognitive flexibility were found to be related to the development, quality and effectiveness of major project managers' relationships with both internal and external stakeholders, and these in turn were associated with their ratings of project success. The research by the authors Serra and Kunc (2015) presented the results of a survey of practitioners in Brazil, the United Kingdom and the United States evaluating the impact of Benefits Realisation Management (BRM) practices on the project success rate. Their results show BRM practices are positive predictors for project success in the creation of 
strategic value for the business. BRM practices can be effective in supporting the successful execution of business strategies. In their papers, the authors Chan and Chan (2004) present an overview of criteria for the assessment of the success of construction projects according to previously conducted research. The criteria on which the majority of pieces of prior research have agreed are the indicators cost, time and quality. Other indicators to be considered are clients, architect, contractor and user (Chan, 2001).

\subsection{Critical Discussion}

A secondary research (literature review) and a primary empirical research (questionnaire survey in the form of structured and semistructured interviews) shows, that the following metrics are generally considered measures of the success of a project:

- The project has conformed to the defined scope, goals and costs.

If the given criteria are fulfilled, the project can be considered successful.

- The customer was satisfied with the project. The project can be considered a success even if a certain aspect of the preceding criterion is not met, though the customer is satisfied with the main aspects of the project. This criterion is becoming increasingly effective and a number of organisations now concentrate on assessing the satisfaction of customers with the project. The information obtained serves them as a basis for overall assessment of project success.

- The project output has fulfilled the principal purpose of the project.

If the main purpose of the project is met by the implementation of the project in spite of the fact that a certain criterion within the triple imperative has not been fulfilled, the project may be considered a success. Specifically, if the outcome of the project was, for example, making certain production processes more effective, which results in financial savings, then the project has been successful even if, for example, the project has taken longer than anticipated in the plan or if the project budget has been exceeded.

An input variable of the expert decisionmaking fuzzy model for the evaluation of project success (see chapter 3 ) was deduced from this information.
Currently analysed models of project success evaluation are based on an isolated application of selection criteria of project success. Those criteria are generally based on the triple imperative of the project - time, cost, quality. The indicators ROI (Return on Investment), NPV (Net Present Value), IRR (Internal Rate of Return) or CBA (Cost-Benefit Analysis) are used especially in terms of financial criteria. The customers and suppliers of the project are also used as criteria for project success evaluation. The project budget (cost of the project) only or time schedule are often used as criteria for project success evaluation. According to this assessment approach is generally not taken into account already achieved quality of the project. It is of course a problem, because the projects who are completed in time and within budget may not have defined outputs (quality of the project). Such a project can't be definitely evaluated as successful. Thoroughly conceived project risk analysis is a prerequisite for maintaining of basic parameters of triple imperative of the project. The projects rated high degree of risk have little potential to be successful in terms of triple imperative of the project. Overall it can be say that the weakness of the existing models for project success evaluation is reflected only selected criteria of project success often in the form of numerical values. The individual characteristics associated with the given process of project management are, it's true, relatively countable in project practice, though generally only with a wide scatter, i.e. they are more or less guesswork anyway. The approach to date, in the area of risk engineering for example, has either applied numerical values of probability and impact directly or worked with the classical strict membership of these values to certain sets which was unsuitable for a number of applications and failed to correspond to the true risk perception.

The proposed model (chapter 3 ) is primarily differed from the current approach thanks its summary evaluation of three key processes that affect the success of the project. It is a process of project risk management, process of elaboration of scheduling and resource analysis and process of quality assurance of the project. It is a process of project risk management, project scheduling and resource analysis and project quality evaluation. The proposed model evaluates these sub- 
processes in three sub-models. The outputs of sub- models are used as inputs to the overall model of project success evaluation. The submodels are possible to use in each life phase of the project also separately. The first submodel evaluates the project status based on the Earned Value Management, specifically the indexes SPI (Schedule performance index) and CPI (Cost performance index). The second sub-model evaluates the total value of project risk on the RIPRAN method, specifically the indicators number of sub-risk and total value of sub-risks. The third sub-model evaluates project quality. Two qualitative indicators were defined to measure the quality of a project in practice (ČSN EN ISO 9000 (010300) 2005; ČSN ISO 10006 (010333) 2004): degree of compliance with the requirements and eligibility for use. The proposed fuzzy model for the assessment of project success is implemented by means of abstract modelling during which it models the structure of the system. The fuzzy approach was used to the modelling of the sub-processes of project success evaluation. This approach minimises a lack to practically application of exact calculation. The advantage of fuzzy sets is the ability to work with vague concepts. These concepts are widely used in everyday project management practice. Systematically, hierarchical and complexly (three key criteria) developed fuzzy model is its main advantage and differ from current project success evaluation models. This fact is confirmed by Assoc. Prof. Branislav Lacko, who is a certified project manager IPMA and longtime active member of Association for Project Management (Společnost pro projektové rízení, 2016) - International Project Management Association (IPMA) is the national organization, where from $2006-2010$ he served as president.

\section{Materials and Methods}

\subsection{Fuzzy Set}

A fuzzy set is a set whose elements have degrees of membership. The fuzzy set was introduced by Lotfi A. Zadeh in 1965 as an extension of the classical notion of sets and can be applied in many fields of human activity (Zadeh, 1965). The degree of membership to fuzzy sets determines "how much" the element belongs to the set. This is the basic principle of fuzzy sets.

A fuzzy set can be defined as follows: Let $X$ be a non-empty set and $\mu_{\tilde{A}}: X \rightarrow[0 ; 1]$.
Then fuzzy set $\tilde{A}$ is a set of all ordered pairs $\left(x, \mu_{A}(x)\right)$ therefore

$$
\tilde{A}=\left\{\left(x, \mu_{\tilde{A}}(x)\right): x \in X, \mu_{\tilde{A}}(x) \in[0 ; 1]\right\} .
$$

where $X$ is a universe, $\mu_{\tilde{A}}$ is a membership function of fuzzy set $\tilde{A}$, (see Fig. 1 ), and $\mu_{\tilde{A}}(x)$ is a grade of membership of $x . \mu_{\tilde{A}}$ is defined for all $x \in X$ and $\mu_{\tilde{A}}(x)=0$ for $x \notin \tilde{A}$.

A support of a fuzzy set $\tilde{A}$ is the classical set

$$
\operatorname{supp} \tilde{A}=\left\{x \in X: \mu_{\tilde{A}}(x)>0\right\} \text {. }
$$

A kernel or core of a fuzzy set $\tilde{A}$ is the classical set

$\operatorname{ker} \tilde{A}=\left\{x \in X: \mu_{\tilde{A}}(x)=1\right\}$.

A height of a fuzzy set $\tilde{A}$ is the number

$$
\text { hgt } \tilde{A}=\sup _{x} \mu_{\tilde{A}}(x) \text {. }
$$

For example, when fuzzy set $\tilde{A}$ is "about 2", see triangular membership function in Figure 1 , then supp $\tilde{A}=(1 ; 3)$, $\operatorname{ker} \tilde{A}=\{2\}$ and hgt $\tilde{A}=1$.

\subsection{Fuzzy Logic}

The application of fuzzy logic is based on fuzzy set theory (Zadeh, 1965; Zimmermann, 2001; Klir \& Yuan, 1995). Fuzzy logic measures the certainty or uncertainty of how much the element belongs to the set. By means of fuzzy logic (Zadeh, 2007) it is possible to find the solution to a given task from rules defined for analogous tasks. The calculation of fuzzy logics consists of three basic steps (Dostál, 2011):

1. Fuzzification - transforms real variables into linguistic variables using their attributes. The variable usually has from three to seven attributes. The attribute and membership functions are defined for input and output variables. The degree of membership of attributes is expressed by a mathematical function - membership function ( $\Pi, Z, S$, etc.).

2. Fuzzy inference - defines the behaviour of a system by using rules of the type $<$ When $>$, $<$ Then> on a linguistic level. Conditional clauses typically have the following form: $<$ When $>$ [Input_a1 <And $>$ Input_a2 <And $>$ $\ldots$ <And $>$ Input_an] < And > [Input_b1 $<$ And $>$ Input_b2 <And $>$... $<$ And $>$ Input_bm] $<$ Then> Output_1. 


\section{Fig. 1: Triangular and trapezoidal type of membership function}



Source: own

Each combination of attributes of input and output variables occurring in a condition $<$ When $>$, <Then>, presents one rule. The rules are created by the user or expert himself.

3. Defuzzification - transfers the results of fuzzy inference (numerical values) on output variables by linguistic values. It describes results verbally.

A system with fuzzy logic works as an automatic system. The user need only enter input data. This can be represented by many variables and their attributes.

\section{Results}

The case study presents the use of fuzzy logic in the evaluation of project success. The Fuzzy Logic Toolbox in MATLAB software was used to create the decision-making model. The expert decision-making fuzzy model system for the evaluation of project success (EDMS PSU) consists of three sub-models: a fuzzy model of project state evaluation (EDMS_PS), a fuzzy model of total project risk evaluation (EDMS_TVPR), and a fuzzy model of project quality evaluation (EDMS_PQ). There are six input variables, four rule blocks and one output variable in the fuzzy model. See Figure 2.
A membership function of type $\Pi$ trapmf (trapezoidal-shaped) was used. The syntax of the function is the following: $y=\operatorname{trapmf}(x,[a b$ $c d]$ ). The description of the trapezoidal curve is a function of a vector $x$ and depends on four scalar parameters $a, b, c, d$, as given by

$$
f(x ; a, b, c, d)=\left\{\begin{array}{cc}
0 ; & x \leq a \\
\frac{x-a}{b-a} ; & a \leq x \leq b \\
1 ; & b \leq x \leq c \\
\frac{d-x}{d-c} & c \leq x \leq d \\
0 ; & d \leq x
\end{array}\right\}
$$

where the parameters a and $d$ locate the "feet" of the trapezoid and the parameters $b$ and $c$ locate the "shoulders".

\section{Fuzzy Sub-Model of Project State Evaluation (EDMS_PS)}

The rule block RB1 evaluates project status (PS) based on the Earned Value Management - EVM (Vanhoucke, 2014), specifically the indexes SPI and CPI. EVM method is based on the following indices:

- Planned value (PV) - Budgeted cost of work scheduled (BCWS). The total PV of a task = the task's budget at completion (BAC). 


\section{Fig. 2: Scheme of project success evaluation}

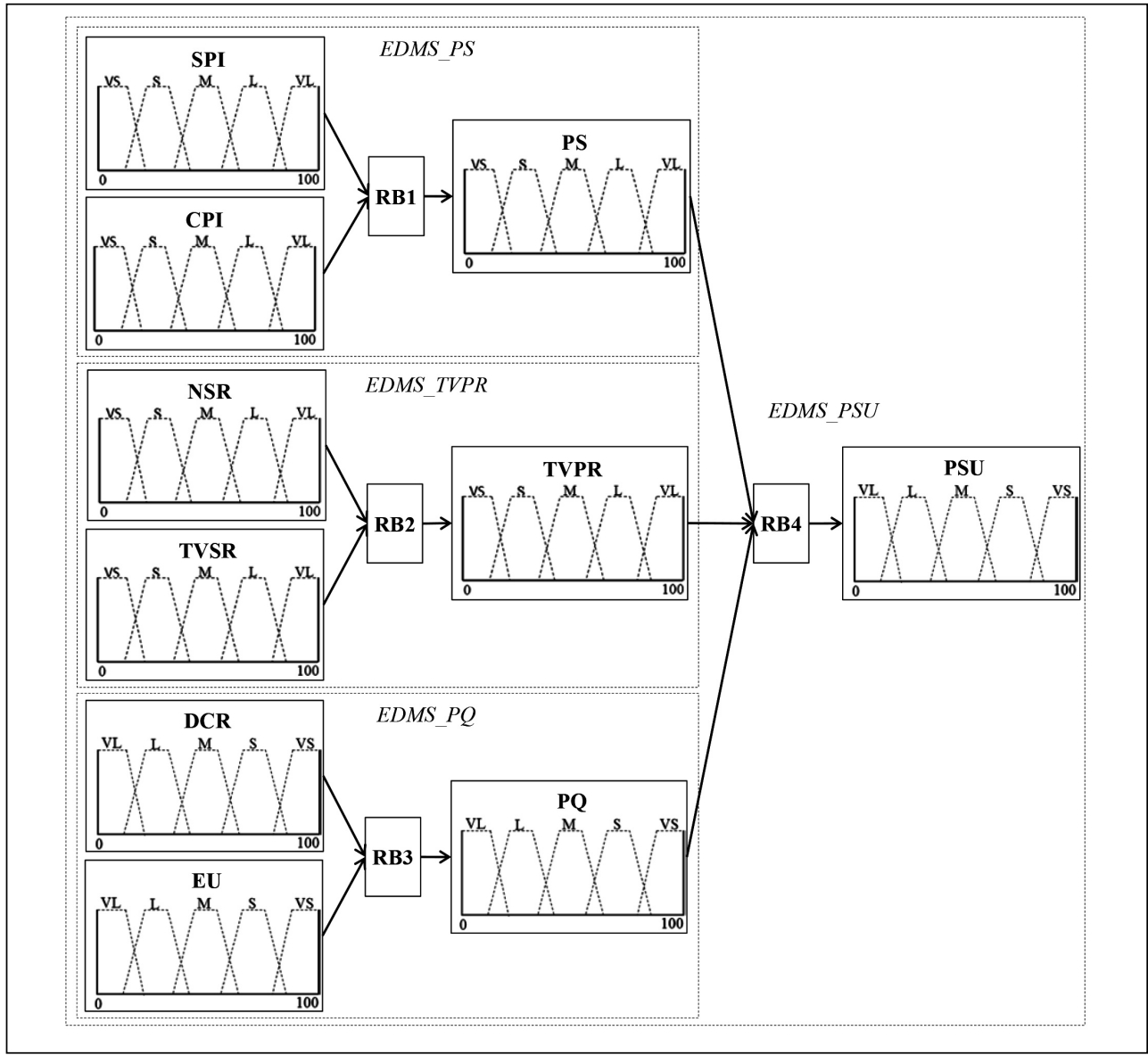

Source: own

- Earned value (EV) - Budgeted cost of work performed (BCWP).

- Actual cost (AC) - Actual cost of work performed (ACWP).

EVM uses for describing project schedule and cost performance following basic indices:

- Schedule variance (SV) - shows whether and by how much your work is ahead of or behind your approved schedule. Mathematically: SV = EV - PV.

- Cost variance (CV) - shows whether and by how much you're under or over your approved budget. Mathematically: $\mathrm{SV}=\mathrm{EV}-\mathrm{AC}$.
- Schedule performance index (SPI) - shows the relative amount the project is ahead of or behind schedule. Mathematically: SPI = EV / PV. Interpretation:

SPI < 1: the project is behind schedule (finish later than expected),

SPI > 1: the project is ahead of schedule (finish sooner than expected),

$\mathrm{SPI}=1$ : the project is on schedule (finish according to schedule).

- Cost performance index (CPI) - shows the relative value of work done compared to the amount paid for it. Mathematically: $\mathrm{CPI}=$ EV / AC. Interpretation:

$\mathrm{CPI}<1$ : the project is over budget, 
CPI > 1: the project is under budget,

$\mathrm{CPI}=1$ : the project is within budget.

There is a graphical representation of $P V$, $E V, A C, B A C, S V$ and $C V$ in Figure 3.

The practical application of EVM is usually defined by certain tolerances which are represented in a graphic circle centred at point $(1,1)$. These circles are the relevant size of the problem in which the project is located problem of project status (PS). The closer to the centre (point $(1,1)$ ), the smaller the problems of project status are. The further away from the centre (point $(1,1)$ ), the greater the problems of project status. See Figure 4.

The inputs (into RB1) are represented by two variables: SPI_deviation (SPI) and CPI_deviation (CPI). The output from rule block $\mathrm{RB} 1$ and the output variable is the problem of project status (PS). The input variable SPI has five attributes: VS - very small, $S$ - small, $M$ - medium, $L$ - large, VL - very large. The input variable CPI has five attributes: VS - very small, $S$ - small, $M$ - medium, L - large, VL - very large. The output variable PS has five attributes: VS - very small, S - small, M medium, L - large, VL - very large (Doskočil, 2015).
Figure 5 shows the rule block (RB1) with 25 rules and degrees of support that set up the relation between input and output variables. The list and combination of rules for the project state evaluation system is based on empirical research in the given subject carried out by the controlled interview technique.

\section{Fuzzy Sub-Model of Total Project Risk Evaluation (EDMS_TVPR)}

The rule block RB2 evaluates the total value of project risk (TVPR) on the RIPRAN (RIsk PRoject ANalysis) method - specifically the indicators: Number of Sub-Risk and Total Value of Sub-Risks. Both indicators are extremely important inputs in the evaluation of the total risk of the project based on the RIPRAN method. The RIPRAN method is an empirical method for the analysis of project risks. The author of the RIPRAN method is Associate Professor Branislav Lacko. The RIPRAN method can be used in all phases of the project (Cooper et al., 2014). The method was originally created for risk analysis automation projects within the framework of a research project at the Technical University in Brno. Experience has shown that, after certain adjustments, it is possible to apply the method in the risk analysis of a wide range

\section{Fig. 3: Graphical representation of basic EVM indices}

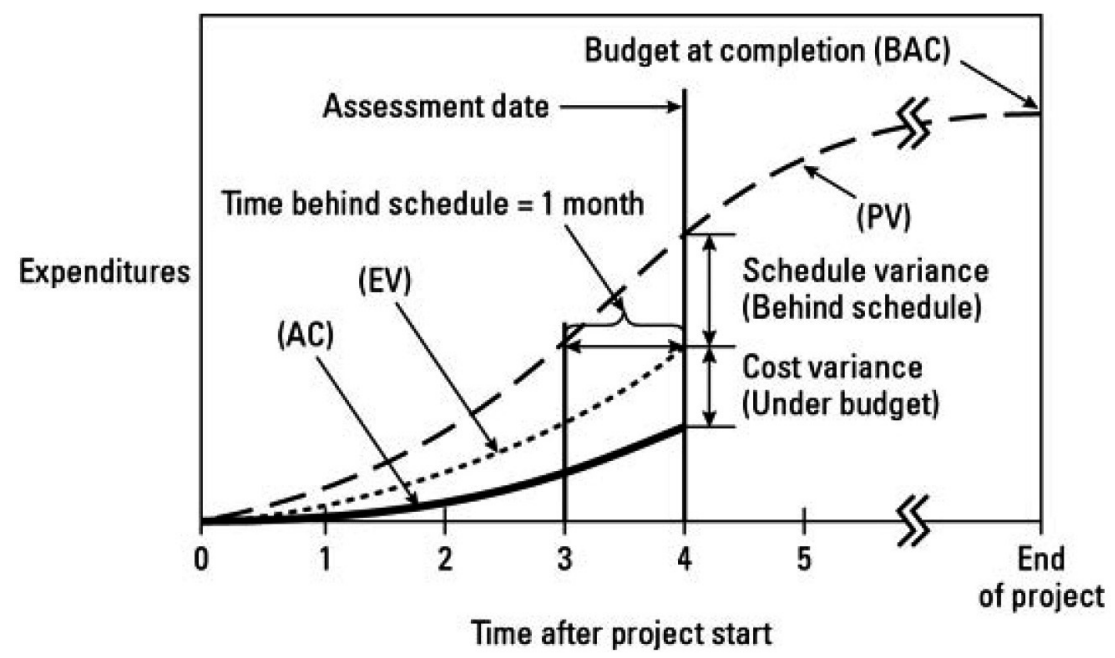

Source: Earned Value Management Terms and Formulas for Project Managers 


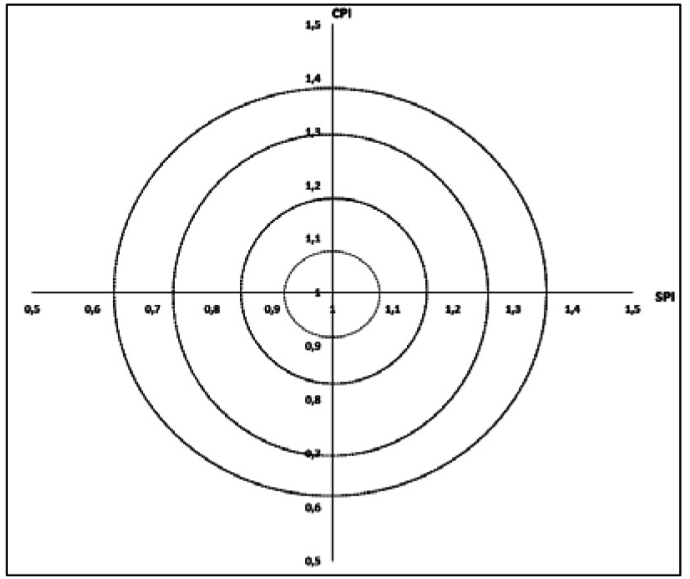

\section{Fig. 5: Rule block (RB1) and some rules - EDMS_PS}

Rule Editor: EDMS_PS

File Edit View Options

1. If (SPI is VS) and (CPI is VS) then (PS is VS) (1)

2. If (SPI is VS) and (CPI is $\mathrm{S}$ ) then (PS is VS) (1)

3. If (SPI is VS) and (CPI is M) then (PS is S) (1)

4. If (SPI is S) and (CPI is VS) then (PS is VS) (1)

5. If ( $(\mathrm{PPI}$ is $\mathrm{S}$ ) and (CPI is $\mathrm{S}$ ) then (PS is $\mathrm{S}$ ) (1)

6. If (SPI is M) and (CPI is VS) then (PS is $S$ ) (1)

7. If (SPI is VS) and (CPI is $L$ ) then (PS is M) (1)

8. If (SPI is S) and (CPI is M) then (PS is M) (1)

9. If ( $\mathrm{SPI}$ is $\mathrm{M}$ ) and (CPI is $\mathrm{S}$ ) then (PS is M) (1)

10. If (SPI is $L$ ) and (CPI is VS) then (PS is M) (1)

11. If ( $\mathrm{SPl}$ is VS) and (CPl is VL) then (PS is $M$ ) (1)

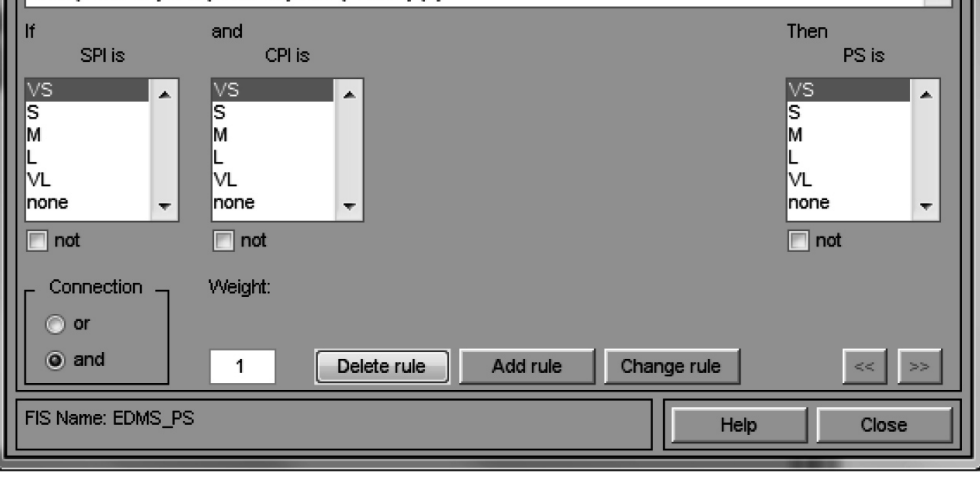


of various projects and, in some cases, for the analysis of other types of risks than project risks. The RIPRAN method is a trademark, registered author of the Industrial Property Office in Prague under reg. no. 283536 (Lacko, 2015).

The inputs (into RB2) are represented by two variables: Number of sub-risk (NSR) and total value of sub-risks (TVSR). The output variable is total value of project risk (TVPR). The input variable NSR has five attributes: VS - very small, $\mathrm{S}$ - small, $\mathrm{M}$ - medium, $\mathrm{L}$ - large, $\mathrm{VL}$ - very large. The input variable TVSR has five attributes: VS - very small, S - small, M - medium, L-large, VL - very large. The output variable TVPR has five attributes: VS - very small, $S$ - small, $\mathrm{M}$ - medium, $\mathrm{L}$ - large, $\mathrm{VL}$ - very large.

Figure 6 shows the rule block (RB2) with 25 rules and degrees of support that set up the relation between input and output variables. The list and combination of rules for the total project risk evaluation system is based on empirical research into the given subject carried out by the controlled interview method.
Fuzzy Sub-Model of Project Quality Evaluation (EDMS_PQ)

Rule block RB3 evaluates project quality (PQ). Two qualitative indicators were defined to measure the quality of a project in practice (ČSN EN ISO 9000 (010300) 2005; ČSN ISO 10006 (010333) 2004):

1. Degree of compliance with the requirements - processes and products of the project correspond to predetermined specifications (declaration of the project).

2. Eligibility for use - the products of the project can be used in the manner for which they were intended.

The inputs (into RB3) are represented by two variables: Degree of compliance with the requirements (DCR) and eligibility for use (EU). The output variable is project quality (PQ). The input variable $D C R$ has five attributes: $V L$ - very large, L-large, M - medium, S - small, VS - very small. The input variable EU has five attributes: $\mathrm{VL}$ - very large, L - large, M - medium,

\section{Fig. 6: Rule block (RB2) and some rules - EDMS_TVPR}

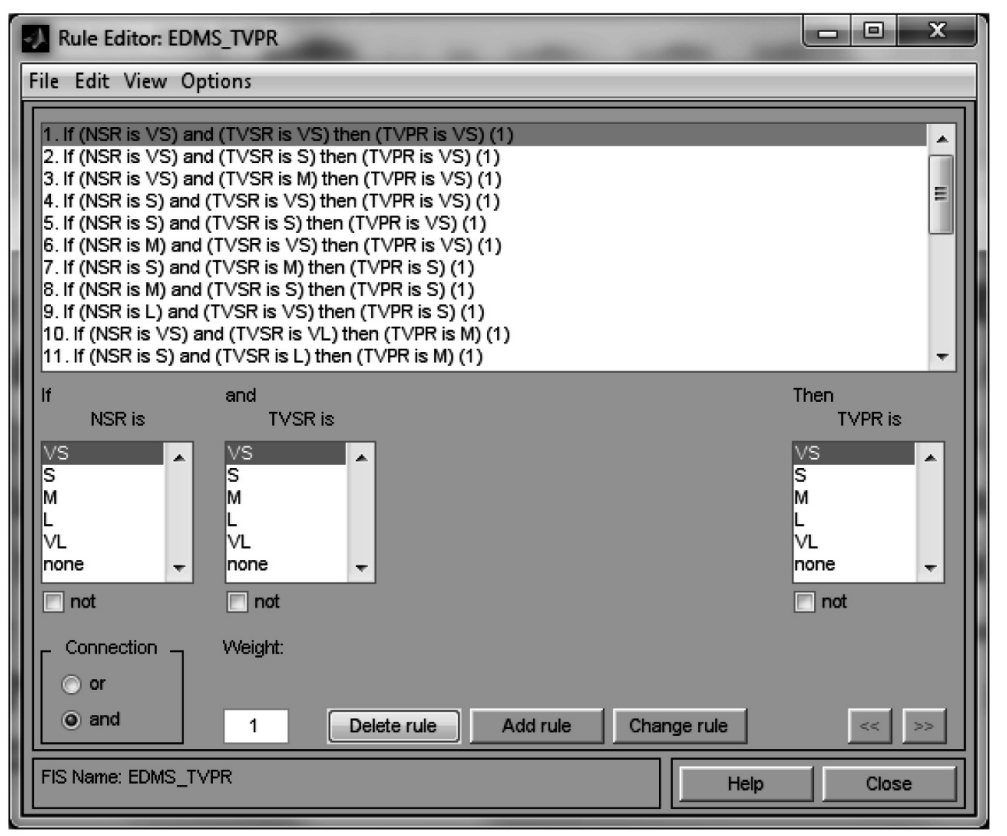


S - small, VS - very small. The output variable $P Q$ has five attributes: $V L$ - very large, $L-$ large, $\mathrm{M}$ - medium, $\mathrm{S}$ - small, VS - very small.

Figure 7 shows the rule block (RB3) with 25 rules and degrees of support that set up the relation between input and output variables. The list and combination of rules for the project quality evaluation system is based on empirical research into the given subject carried out by the controlled interview method.

The scheme of the fuzzy model evaluating project success (only the sub-model related to rule block RB4) is displayed in Figure 8.

\section{Fuzzy Model of Project Success Evaluation (EDMS_PSU)}

Rule block RB4 evaluates project success (PSU). Partial outputs from the blocks (RB1, $\mathrm{RB} 2, \mathrm{RB} 3$ ) are simultaneously inputs into rule block RB4 (see Fig. 7). The output variable is project success (PSU). The output variable PSU has five attributes: $V L$ - very large, $L$ - large, $\mathrm{M}$ - medium, $\mathrm{S}$ - small, VS - very small.

Figure 9 shows the rule block (RB4) with 125 rules and degrees of support that set up the relation between input and output variables. The list and combination of rules for the project success rate evaluation system is based on empirical research into the given subject carried out by the controlled interview technique.

Figure 10 shows the correlation between input and output. Specifically, this image shows graphically the correlation between two output variables PSU and input variables $P S$ and TVPR. It is a function dependence $P S U=f(P S$, TVPR, $P Q)$, where the input variable $P Q$ in this three-dimensional graph is a constant. The user can change this variable for presentation in graphs. In this graph, you can see extremely important information about the fuzzy model.

The graphic representation of the dependence of the input and output variables

\section{Fig. 7: Rule block (RB3) and some rules - EDMS_PQ}

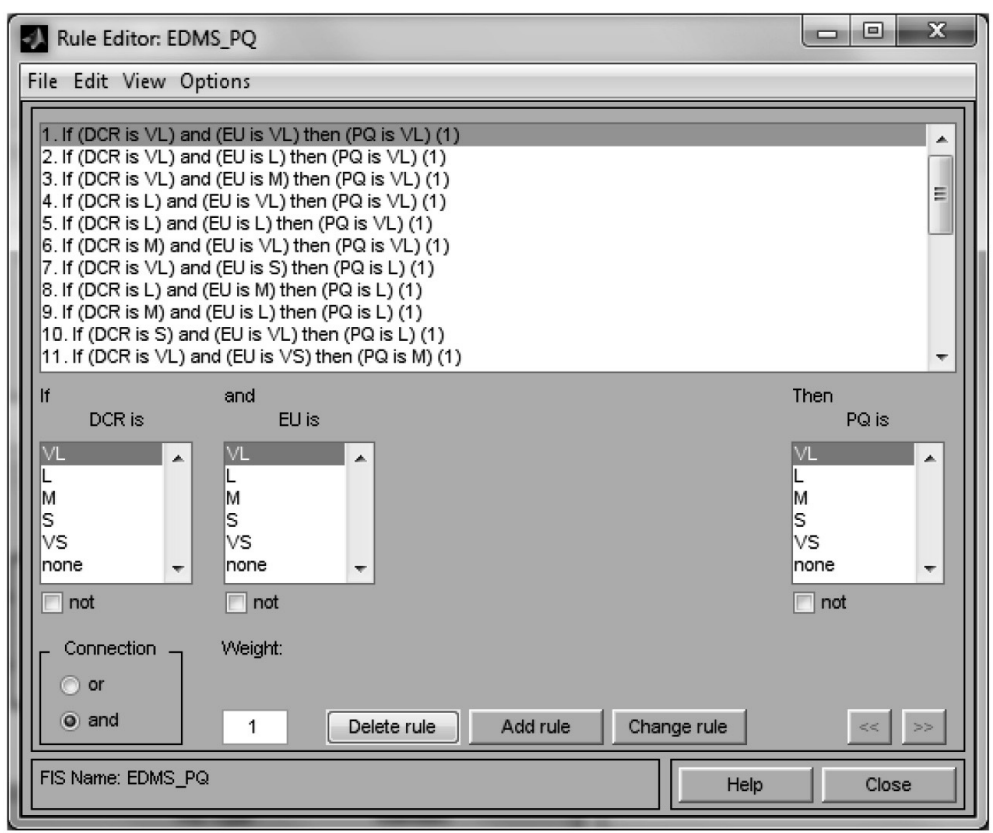




\section{Informační management}

\section{Fig. 8: Build up model - RB4}

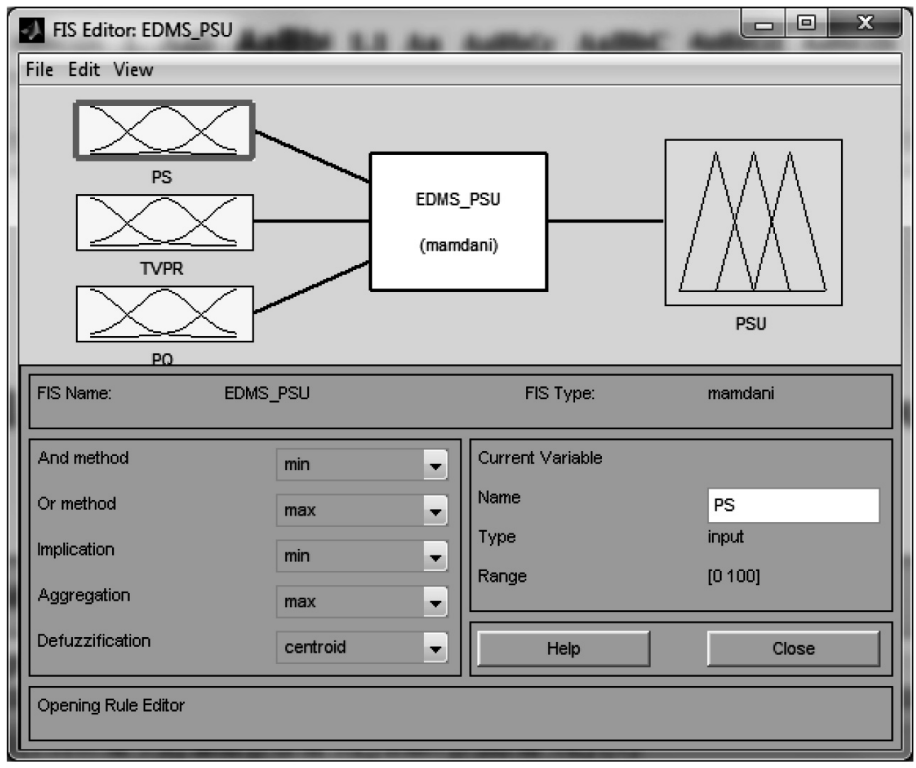

Source: own

\section{Fig. 9: Rule block (RB4) and some rules - EDMS_PSU}

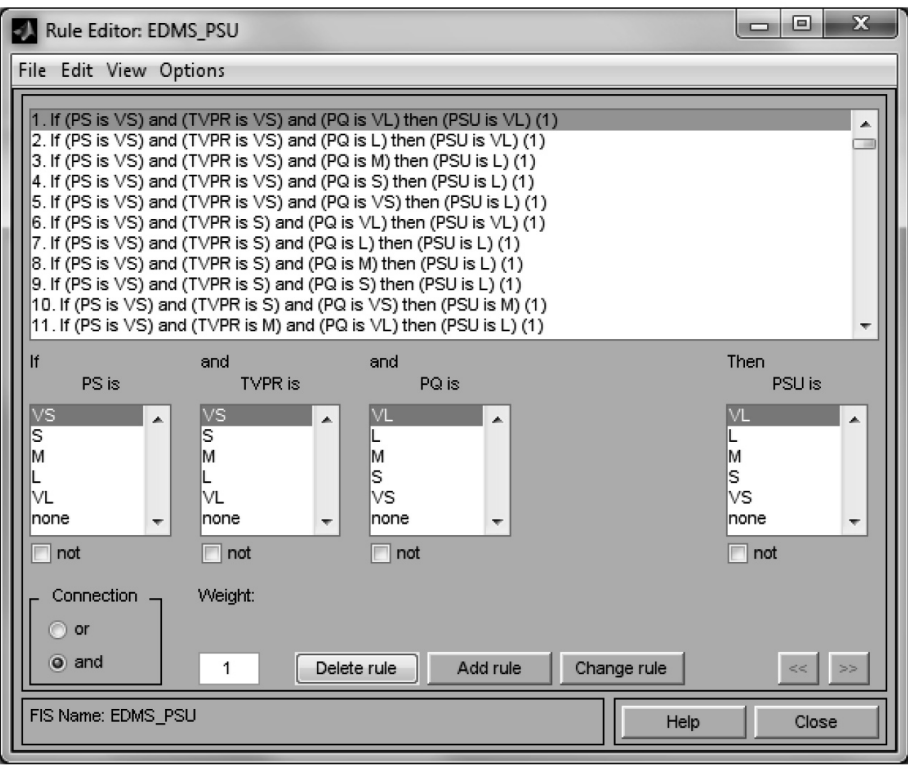


makes it possible to control the set parameters of the fuzzy model. In general, one may say that the display area of the given model is satisfactory since the defined rules and selected membership functions generalise the model sufficiently.

Taking into account the monitoring of four variables (four-dimensional problem), which is our idea difficult to imagine, Figure 10 shows a cut of the four-dimensional problem; the result is three dimensions surface. This is achieved by fixing one of the input variables, e.g. the third input variable $P Q=50$, see Figure 10 . The value of output variable (PSU) reaches the maximum only in the value 75 on this level of the cut, see Figure 10.

The display of four-dimensional problem is reduced into three dimensions for a fixes selected input variable $P Q=50$. The changing variables are PS, TVPR, PSU. The points in the graph (see Fig. 10) have therefore coordinates [PS, TVPR, PSU]. It is possible to deduct for variables $P S=0$ and TVPR $=0$ the value of $P S U=0$. For variables $P S=100, T V P R=100$ can be deduct the value of $P S U=75$. See Figure 10.

Figure 11 shows the evaluation of project success for a concrete project. The input variables are set up as $P S=0$, TVPR $=0, P Q=$ 0 . This leads to the result (output) PSU $=7.29$ which means that project success is evaluated as very large (the value 7.29 is close to zero). Using the first rule is expressed by the output variable PSU coloration (see Fig. 11). It was used the first rule: If (PS is VS) and (TVPR is $V S$ ) and ( $P Q$ is $V L$ ) then ( $P S U$ is $V L)$. See Figure 9. This rule means: If project status (PS) is evaluated as very small (VS), total value of project risk (TVPR) is evaluated as very small (VS) and project quality (PQ) is evaluated as very large (VL) then project success (PSU) is evaluated as very large (VL).

The input variables in value $P S=100, T V P R$ $=100, P Q=100$ leads to the result (output) $\mathrm{PSU}=92.7$ which means that project success is evaluated as very small. It was used the last rule: If ( $P S$ is VL) and (TVPR is VL) and ( $P Q$ is $V S$ ) then (PSU is VS). This rule means: If project status (PS) is evaluated as very large (VL), total value of project risk (TVPR) is evaluated as very large (VL) and project quality (PQ) is evaluated as very small (VS) then project success (PSU) is evaluated as very small (VS).

\section{Discussion}

The proposed fuzzy model for the assessment of project success is implemented by means of abstract modelling during which it models the structure of the system. All figures created in the Fuzzy Logic Toolbox in MATLAB software are illustrative. The fuzzy modelling of selected project processes (the project status evaluation, the project risk evaluation and the project quality evaluation) was applied, first and foremost, in view of the ability of fuzzy sets to work with inexact (vague) concepts. These concepts are widely used in everyday project practice. Definition of exact mathematical relationships that would model the given reality sufficiently faithfully would be highly complicated in this situation.

The success of the proposed model and its limitations depend, first and foremost, on the extent and quality of the input data. The proposed model is set to expert data. This data served as a point of departure for the description of the modelled system from the viewpoint of its purpose and goals. The model contains basic input variables that have long been considered in project practice as criteria for the assessment of pertinent project processes. If other facts or additional new data is identified, additional or other possible dependences may be determined or the given dependences exactified, with the rules and shapes of functions of model membership thereby being exactified as well. The structure rules of the fuzzy model depend also on life phase of the project. Priorities of the project (thanks to the environment in which the projects underway) are changing. Experts can therefore define different rules for each life phase of the project. For these reasons, the proposed model cannot be considered final. The viability of the model, which falls over time, must always be respected. The model must be upgraded, i.e. corrections with regard to the real state must be made or the model drawn up entirely from scratch. Only a model drawn up to a high standard and subjected to verification can be applied in live operations and used as a tool supporting decision-making.

The model must be tuned and verified after its creation. The success of the model depends primarily on the quality of the fuzzy rules. If the model does not give correct output, the rules or shapes of the membership functions must be corrected or changed. The results meet the requirements, for which reason the model can be considered generally functional. The model 


\section{Fig. 10: Correlation between variables - RB4}

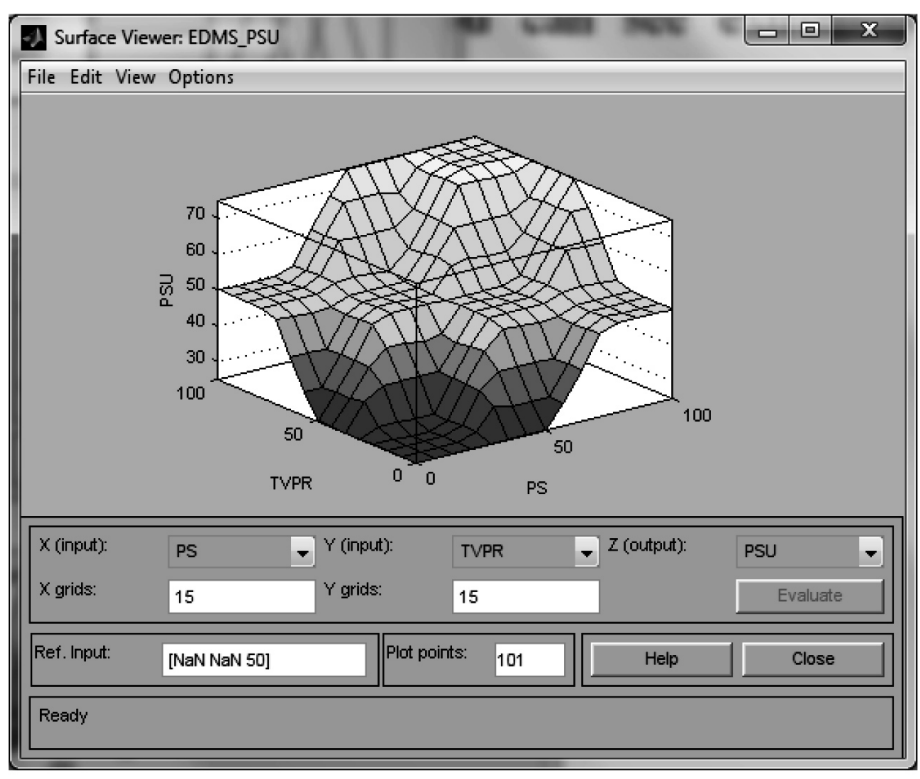

\section{Fig. 11: Output (PSU) - project success is very large}

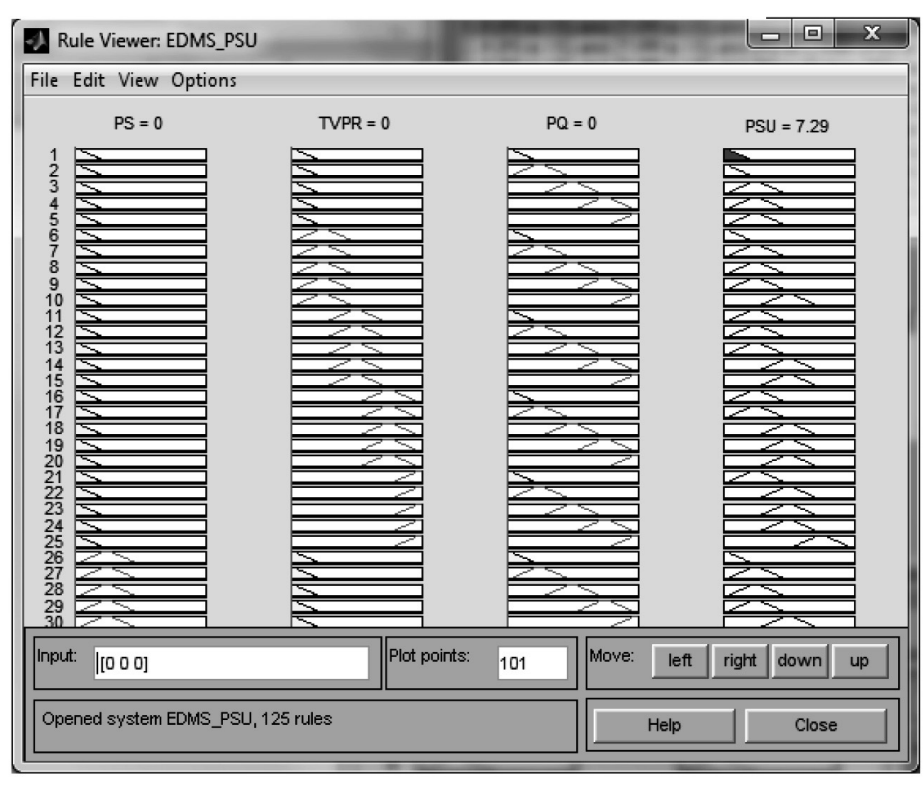


can be used in practice. An executable file called M-File can be created to implement the fuzzy model in MATLAB. M-file is used to enter the input values and automatically evaluate project success.

The proposed fuzzy model is recommended for use primarily in the implementation phase of the project cycle and then repeatedly after each project milestone is reached (structured, for example, according to WBS - Work Breakdown Structure). Project managers obtain a tool for "measuring" selected project processes with this model. They also get the opportunity of using the model for experimentation, for example by means of simulations. This provides additional information about possible project development and, in some cases, alarm signals to support future decision-making.

\section{Conclusion}

This paper presents an expert decision-making fuzzy model for evaluating project success. The proposed model (including sub-models) is implemented in the MATLAB software environment with the use of the Fuzzy Logic Toolbox application where it is also verified and further specified. MATLAB software was chosen for the construction of models in view of the fact that it is not necessary to perform a detailed examination of the essence of the principle of fuzzy sets (with which fuzzy logic works) which is an indisputable advantage in view of the varying standard of mathematics in the intercultural environment of project teams today.

In view of today's multidisciplinary and international project environment, characterised by a large number of parties with an interest in the project, the fuzzy approach is one way of incorporating uncertainty into project practice. The advantage of fuzzy sets over classical set theory lies in their ability to record inexact (vague) concepts that project managers use in their natural language in the design and implementation of projects. The individual characteristics associated with the given process of project management are, it's true, relatively countable in project practice, though generally only with a wide scatter, i.e. they are more or less guesswork anyway. The approach to date, in the area of risk engineering for example, has either applied numerical values of probability and impact directly or worked with the classical strict membership of these values to certain sets which was unsuitable for a number of applications and failed to correspond to the true risk perception. The fuzzy approach to the modelling of these processes minimises this shortcoming. The application of fuzzy approaches in the modelling of controversial (in relation to the possibility and practical usability of exact calculation) selected project processes is one of the principal contributions of this paper.

The proposed model provides project managers and others with a tool for the "measurement" of selected project processes (assessment of the state of the project, assessment of project risks, assessment of project quality, assessment of project success). The fuzzy approach including knowledge base of expert rules and its ability to systematically, hierarchical and comprehensively evaluate three key criteria of project success is the main asset and simultaneously differ from current models. A significant general advantage of the application of the technique of modelling in project management is the possibility of subsequent experimentation with the model, in the form of simulation for example. This makes further information about the possible variant development of projects available and can provide warning signals to support future decision-making.

This paper was supported by grant FP-S-15-2787 "Effective Use of ICT and Quantitative Methods for Business Processes Optimisation" from the Internal Grant Agency at Brno University of Technology.

\section{References}

Balkienè, K. (2013). Sustainable innovativeness: issues and public policy. Journal of Security and Sustainability Issues, 3(2), 53-76. doi:10.9770/jssi.2013.3.2(5).

Bočková, H. K., Vořechová, E., \& Valenta, K. (2005). State of the Project Management Practice in the Czech Republic - the Research Methodology Framework. E\&M Ekonomie \& Management, 8(3), 79-84.

Bushan, R. P., \& Ravi, S. N. (2012). Fuzzy Critical Path Method Based on Lexicographic Ordering of Fuzzy Numbers. Pakistan Journal of Statistics \& Operation Research, 8(1), 139-154.

Chan, A. (2001). Framework for measuring success of construction projects (Report). Brisbane: CRC for Construction Innovation. 
Chan, A. P. C., \& Chan, A. P. L. (2004). Key performance indicators for measuring construction success. Benchmarking: An International Journal, 11(2), 203-221. doi:10.1108/14635770410532624.

Chanas, S., \& Zielinski, P. (2001). Critical path analysis in the network with fuzzy activity times. Fuzzy sets and Systems, 122(2), 195204. doi:10.1016/S0165-0114(00)00076-2.

Chipulu, M. et al. (2014). Exploring the impact of cultural values on project performance: The effects of cultural values, age and gender on the perceived importance of project success/failure factors. International Journal of Operations \& Production Management, 34(3), 364-389. doi:10.1108/IJOPM-04-2012-0156.

Colin, J., \& Vanhoucke, M. (2016). Empirical Perspective on Activity Durations for ProjectManagement Simulation Studies. Journal of Construction Engineering and Management, 142(1). doi:10.1061/(ASCE)CO.1943-7862.0001022.

Cooper, D. et al. (2014). Project Risk Management Guidelines: Managing Risk with ISO 31000 and IEC 62198. Wiley.

Cummings, S., Bridgman, T., Brown, K. G. (2016). Unfreezing change as three steps: Rethinking Kurt Lewin's legacy for change management. Human Relations, 69(1), 33-60. doi:10.1177/0018726715577707.

Davis, K. (2014). Different stakeholder groups and their perceptions of project success. International Journal of Project Management, 32(2), 189-201. doi:10.1016/j.jproman.2013.02.006.

de Carvalho, M. M., Patah, L. A., Bido, D. de S. (2015). Project management and its effects on project success: Cross-country and crossindustry comparisons. International Journal of Project Management. 33(7), 1509-1522. doi:10.1016/j.jproman.2015.04.004.

Doskočil, R. (2015). Fuzzy logic: An instrument for the evaluation of project status. Revista de Metodos Cuantitativos para la Economia y la Empresa. 19(1), 5-23.

Doskočil, R., \& Doubravský, K. (2013). Critical Path Method based on Fuzzy Numbers: Comparison with Monte Carlo Method. In Creating Global Competitive Economies (pp. 1402-1411). Rome: International Business Information Management Association.

Dostál, P. (2011). Advanced Decision Making in Business and Public Services. Brno: CERM.

Dudzevičiūtè, G., \& Tvaronavičienè, M. (2011). Measurement framework of innovation activity: theoretical approaches' analysis. Journal of Security and Sustainability Issues, 1(1), 63-75.

Earned Value Management Terms and Formulas for Project Managers. Retrieved March 31, 2016, from http://www.dummies.com/ how-to/content/earned-value-managementterms-and-formulas-for-pro.html.

Grossmann, V. (2009). Entrepreneurial innovation and economic growth. Journal of Macroeconomics, 31(4), 602-613. doi:10.1016/j. jmacro.2008.12.008.

Jaradat, A. R., \& Andreica, C. M. H. (2010). The Cost-Benefit Analysis in the Management of the Investment Projects. Metalurgia International, 15, 173-175.

Joslin, R., \& Muller, R. (2015). Relationships between a project management methodology and project success in different project governance contexts. International Journal of Project Management. 33(6), 1377-1392. doi:10.1016/j.ijproman.2015.03.005.

Kemmeter, S. (2014). By Controlling for Project Success - Partnership Strategies for Controller and Manager. Betriebswirtschaftliche Forschung und Praxis, 66(5), 579-580.

Khan, A. S., \& Rasheed, F. (2015). Human resource management practices and project success, a moderating role of Islamic Work Ethics in Pakistani project-based organizations. International Journal of Project Management, 33(2), 435-445. doi:10.1016/j. ijproman.2014.08.006.

Klir, G. J., \& Yuan, B. (1995). Fuzzy Sets and Fuzzy Logic, Theory and Applications. New Jersey: Prentice Hall.

Kloppenborg, T. J. et al. (2014). Project Success and Executive Sponsor Behaviors: Empirical Life Cycle Stage Investigations. Project Management Journal, 45(1), 9-20. doi:10.1002/pmj.21396.

Kuchta, D. (2001). Use of Fuzzy numbers in project risk (criticality) assessment. International Journal of Project Management, 19(5), 305-310.

Kuo, Y.-C., \& Lu, S.-T. (2013). Using fuzzy multiple criteria decision making approach to enhance risk assessment for metropolitan construction projects. International Journal of Project Management, 31(4), 602-614. doi:10.1016/j.ijproman.2012.10.003.

Lacko, B. (2015). RIPRAN Metoda pro hodnoceni projektových rizik. Retrieved March 19, 2015, from http://ripran.cz/licence.html. 
Liu, Z. C., \& Ye, Y. (2015). Models for comprehensive evaluating modeling of investment project risk with trapezoid fuzzy linguistic information. Journal of Intelligent \& Fuzzy Systems, 28(1), 151-156. doi:10.3233/IFS-141284.

Mazur, A. et al. (2014). Rating defence major project success: The role of personal attributes and stakeholder relationships. International Journal of Project Management, 32(6), 944-957. doi:10.1016/j.ijproman.2013.10.018.

McKay, D. S., \& Ellis, T. J. (2014). Tracking the Flow of Knowledge in IT organizations; The Impact of Organizational Learning Factors and Project Learning Practices on Project Success. Proceedings of the 2014 47th Hawaii International Conference on System Sciences (pp. 5185-5194). Washington, D.C.: IEEE Computer Society.

Naeni, L. M., \& Salehipour, A. (2011). Evaluating fuzzy earned value indices and estimates by applying alpha cuts. Expert Systems with Applications, 38(7), 8193-8198. doi:10.1016/j.eswa.2010.12.165.

Naeni, L. M., Shadrokh, S., Salehipour, A. (2011). A fuzzy approach for the earned value management. International Journal of Project Management, 29(6), 764-772. doi:10.1016/j. ijproman.2013.02.002.

Nasirzadeh, F. et al. (2014). Dynamic modeling of the quantitative risk allocation in construction projects. International Journal of Project Management, 32(3), 442-451. doi:10.1016/j.ijproman.2013.06.002.

Nieto-Morote, A., \& Ruz-Vila, F. (2011). A fuzzy approach to construction project risk assessment. International Journal of Project Management, 29(2), 220-231. doi:10.1016/j.ijproman.2010.02.002.

Oliveros, A. V. O., \& Fayek, A. R. (2005). Fuzzy Logic Approach for Activity Delay Analysis and Schedule Updating. Journal of Construction Engineering and Management, 131(1), 42-51. doi:10.1061/(ASCE)07339364(2005)131:1(42).

Relich, M. (2015). A computational intelligence approach to predicting new product success. In Proceedings of the 11th International Conference on Strategic Management and its Support by Information Systems (pp. 142-150).

Relich, M., \& Muszyński, W. (2014). The use of intelligent systems for planning and scheduling of product development projects. Procedia computer science, 35, 1586-1595. doi:10.1016/j.procs.2014.08.242.
Rodriguez, A., Ortega, F., \& Concepcion, R. (2016). A method for the evaluation of risk in IT projects. Expert Systems with Applications, 45(March), 273-285. doi:10.1016/j.eswa.2015.09.056.

Rudnik, K., \& Deptula, A. M. (2015). System with probabilistic fuzzy knowledge base and parametric inference operators in risk assessment of innovative projects. Expert Systems with Applications, 42(17), 6365-6379. doi:10.1016/j.eswa.2015.04.025.

Samset, K. (1998). Project management in a high-uncertainty situation: Uncertainty, risk and project management in international development projects (Doctoral dissertation). Trondheim: Norwegian University of Science and Technology, Faculty of Civil and Environmental Engineering, Department of Building and Construction Engineering.

Společnost pro projektové řízení Česká republika. (2016). Retrieved March 31, 2016, from http://cspr.cz/.

Schibi, O. (2013). Managing Stakeholder Expectations for Project Success. A Knowledge Integration Framework and Value Focused Approach. Plantation: J. Ross Publishing.

Schwable, K. (2011). Řízení projektů v IT, Kompletní průvodce. Brno: Computer Press.

Serra, C. E. M., \& Kunc, M. (2015). Benefits Realisation Management and its influence on project success and on the execution of business strategies. International Journal of Project Management, 33(1), 53-56. doi:10.1016/j.jproman.2014.03.011.

Todorovic, M. L., Petrovic, D. C., Mihic, M. M., Obradovic, V. L., \& Bushuyev, S. D. (2015). Project success analysis framework: A knowledge-based approach in project management. International Journal of Project Management, 33(4), 772-783. doi:10.1016/j.ijproman.2014.10.009.

Úřad pro technickou normalizaci, metrologii a státní zkušebnictví. (2005). ČSN EN ISO 9000 (010300) Systémy managementu kvality - Základní principy a slovník. Praha: Úřad pro technickou normalizaci, metrologii a státní zkušebnictví.

Úřad pro technickou normalizaci, metrologii a státní zkušebnictví. (2004). ČSN ISO 10006 (010333) Systémy managementu jakosti Směrnice pro management jakosti projektů. Praha: Úřad pro technickou normalizaci, metrologii a státní zkušebnictví.

Vanhoucke, M. (2014). Earned Value Management. In Integrated Project Management 


\section{Informační management}

and Control, Management for Professionals (pp. 17-31). Springer International Publishing. doi:10.1007/978-3-319-04331-9_2.

Wauters, M., \& Vanhoucke, M. (2016). A comparative study of Artificial Intelligence methods for project duration forecasting. Expert Systems with Applications, 46(March), 249261. doi:10.1016/j.eswa.2015.10.008.

Wimelius, M. E., \& Engberg, J. (2015). Crisis Management through Network Coordination: Experiences of Swedish Civil Defence Directors. Journal of Contingencies and Crisis Management, 23(3), 129-137. doi:10.1111/1468-5973.12048.

Yang, L.-R., Huang, C.-F., \& Wu, K.-S. (2011). The association among project manager's leadership style, teamwork and project success. International Journal of Project Management, 29(3), 258-267. doi:10.1016/j.jproman.2010.03.006.

Yin-xiang, L. (2013). The rules and Models to Estimate IRR Conveniently and Effectively. New York: IEEE.

Zadeh, L. A. (1965). Fuzzy sets. Information and Control, 8(3), 338-353. doi:10.1016/S00199958(65)90241-X.

Zadeh, L. A. (2007). Fuzzy logic as the logic of natural languages. In P. Melin, O. Castillo, E. G. Ramirez, J. Kacprzyk, \& W. Pedrycz. (Eds.), Analysis and Design of Intelligent Systems Using Soft Computing Techniques (pp. 1-2). Berlin: Springer-Verlag.
Zhang, S. X., \& Li, X. L. (2011). Construction Project Risk Assessment Model. In 4th International Conference on Engineering and Risk Management (ERM) (pp. 42-45). Toronto.

Zimmermann, H. J. (2001). Fuzzy Set Theory - and its Applications (4th ed.). London: Kluwer Academic Publishers.

Zwikael, O. et al. (2014). The moderating effect of risk on the relationship between planning and success. International Journal of Project Management, 32(3), 435-441. doi:10.1016/j.jproman.2013.07.002.

Ing. Radek Doskočil, Ph.D., MSc

Brno University of Technology Faculty of Business and Management Department of Informatics doskocil@fbm.vutbr.cz

doc. Ing. et Ing. Stanislav Škapa, Ph.D. Brno University of Technology Faculty of Business and Management

Department of Economics skapa@fbm.vutbr.cz

Ing. Petra Olšová. Ph.D. Jan Evangelista Purkyně University in Ústí nad Labem

Faculty of Social and Economic Studies Department of Regional and Local Development petra.olsova@ujep.cz 


\section{Abstract}

\section{SUCCESS EVALUATION MODEL FOR PROJECT MANAGEMENT}

\section{Radek Doskočil, Stanislav Škapa, Petra Olšová}

The article presents an expert fuzzy model for evaluation of the project success rate. The model is implemented with the use of fuzzy logic. First, fundamental theoretical principles related to the problems of project success rate, fuzzy sets and fuzzy logic are introduced, after which a fuzzy model for project success rate evaluation, including partial sub-models, is presented in the form of a case study which represents the main goal of the article.

The fuzzy model is implemented in the MATLAB software environment with the use of the Fuzzy Logic Toolbox application, where it is also verified and further specified. The fuzzy model consists of six input variables which are divided according to their character into three categories in each block (RB1, RB2, RB3) and are separately evaluated. Partial outputs from the blocks (RB1, RB2, $R B 3)$ are simultaneously inputs for block RB4, from which there is a single output variable - project success (PS). The RB1 rule block evaluates the situation from the point of view of the state of the project. The RB2 rule block evaluates the total value of project risk. The $R B 3$ rule block evaluates project quality. The RB4 rule block evaluates the total project success rate.

Experimenting with the fuzzy model allows simulation of the uncertainty that is always involved in projects. The case study introduces an overall diagram of the fuzzy model, the input and output variables, including their attributes, and the evaluation rules of the four rule blocks.

The proposed fuzzy model is used to evaluate project success primarily in the implementation phase, then repeatedly after each phase of the project is completed. This provides project managers with a tool that allows relatively rapid evaluation of the success of the project and the opportunity of applying appropriate measures in good time if necessary.

Key Words: Project management, project success, evaluation model, fuzzy logic, decisionmaking.

JEL Classification: C44, M11, M21.

DOI: 10.15240/tul/001/2016-4-012 